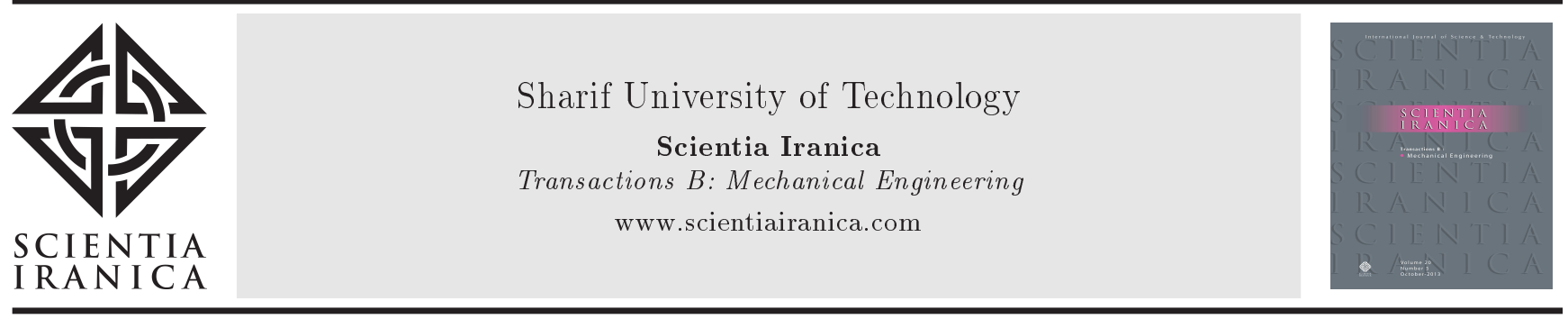

\title{
Economic and environmental evaluation of different operation alternatives to aquifer thermal energy storage in Tehran, Iran
}

\author{
H. Ghaebi ${ }^{a, *}$, M.N. Bahadori ${ }^{b}$ and M.H. Saidi ${ }^{b}$ \\ a. Department of Mechanical Engineering, Faculty of Engineering, University of Mohaghegh Ardabili, Ardabil, P.O. Box 179, Iran. \\ b. School of Mechanical Engineering, Sharif University of Technology, Tehran, P. O. Box 11155-9567, Iran.
}

Received 10 April 2015; received in revised form 14 January 2016; accepted 2 May 2016

\author{
KEYWORDS \\ Aquifer thermal \\ energy storage; \\ Economic evaluation; \\ Environmental \\ evaluation.
}

\begin{abstract}
Aquifers are underground porous formations containing water. Confined aquifers are surrounded by impermeable layers on top and bottom, called cap rocks and bed rocks. A confined aquifer with a very low groundwater flow velocity was considered to meet the annual cooling and heating energy requirements of a residential building complex in Tehran, Iran. Three different alternatives of Aquifer Thermal Energy Storage (ATES) were employed to meet the heating/cooling demands of the buildings. These alternatives were using ATES for: cooling alone, heating alone by coupling with flat-plate solar collectors, and cooling and heating by coupling with a heat pump. For the economic evaluation of the alternatives, a life cycle cost analysis was employed. For the environmental evaluation, Ret Screen software was employed. For the considered 3 operational alternatives, using ATES for cooling alone had the minimum payback period time of 2.41 years and the life cycle cost of $16000 \$$. In the environmental perspective, among the 3 alternatives, coupling of ATES with heat pump for cooling and heating had the minimum $\mathrm{CO}_{2}$ generation, corresponding to 359 tons/year.
\end{abstract}

C 2017 Sharif University of Technology. All rights reserved.

\section{Introduction}

Nowadays, $40 \%$ of energy consumption and greenhouse gas (GHG) emissions of developed economies are related to buildings and $55 \%$ of building energy usage is for heating and cooling. The reduction of buildingrelated GHG emissions is a high international policy priority. Since there are many technical solutions, these policies should involve significant improvements in the use of highly energy-efficient systems [1].

To reduce the energy consumption and the emission of GHG, the building sector needs energy efficient solutions operating at the lowest cost.

\footnotetext{
*. Corresponding author. Tel./Fax: +984533512912

E-mail address: hghaebi@uma.ac.ir (H. Ghaebi)
}

In relation with energy and buildings, sustainable engineering requires:

1. Reduction of the heating and cooling energy needs of buildings to their minimum possible values;

2. Reduction of consumption of primary sources of energy to meet these minimum values through innovative designs of energy conversion systems and the employment of innovative methods to meet the energy demands.

Seasonal storage of thermal energy in aquifers and the utilization of solar energy and heat pumps are examples of innovative approaches to reduce primary energy demand for heating and cooling of buildings. Furthermore, ATES is technically and economically feasible [2-4]. 
Recently, ATES has become more popular, considering the problems caused by the depletion of fossil fuels and the increase of global warming [5,6]. Aquifer Thermal Energy Storage (ATES) systems are generally considered to be economically viable for the seasonal storage of thermal energy. In an ATES, contamination and depletion of groundwater are minimal, since the water withdrawn from aquifer is circulated through a heat exchanger and it is immediately injected back into the aquifer though injection well(s) [7-9].

Sommer et al. [10] determined the thermal performance of large-scale application of ATES using a simplified hydrogeological model. They compared the different zonation patterns and determined the influence of well-to-well distances. The role of aquifer thickness, thermal radius, and heat loss through the upper and lower confining aquitards was discussed. Jeon et al. [11] conducted a sensitivity analysis of recovery efficiency in two cases of high-temperature ATES system with a single well to select key parameters. For a fractional factorial design used to choose input parameters with uniformity, they considered the optimal Latin hypercube sampling with an enhanced stochastic evolutionary algorithm. Then, the recovery efficiency was obtained using a computer model developed by COMSOL multiphysics. They concluded that key parameters varied with the experimental domain of hydraulic and thermal properties as well as the number of input variables. Bloemendal et al. [12] described what optimal and sustainable use of the subsurface would look like in relation to ATES systems. With simulations, they showed their impact on the subsurface and described the current way of dealing with these impacts in the Netherlands. They also considered self-organization and self-governance to improve the adoption and operation of ATES. Zeghicia et al. [13] assessed the suitability of using heat and cold storage in a single deep geothermal aquifer for district heating and cooling. They used an integrated modelling approach for evaluating the controls on the energy efficiency of High-Temperature Aquifer Thermal Energy Storage (HT-ATES). They also analyzed sensitivity of the system efficiency with respect to the main physical (density, viscosity, and longitudinal dispersivity) and operational (distance between warm and cold storage volumes, flow rates) design parameters.

In 2007, Sethia and Sharma [14] conducted an economic evaluation of an aquifer and its combination with a heat exchanger for heating and cooling of a greenhouse. The payback period in this project was 3.5 years. It was more economical than the conventional heating/cooling system, which had a payback period of 7 years. They also employed a thermo-economic analysis for the economic evaluation of the system [15]. Gaine and Duffy [16] employed a Life Cycle Cost (LCC) method in their economic analysis of a borehole ther- mal energy storage system. They considered capital and operational costs, and calculated the costs of the recovered energy for different scenarios. Vanhoudt et al. [17] monitored the performance of an aquifer thermal energy storage system in combination with a heat pump for heating, cooling, and the ventilation of air in a Belgian hospital for a period of three years. Furthermore, they conducted an economic analysis and showed an annual cost reduction of $54000 €$, when compared with the basic case with the payback time of 3.9 years.

Zhua et al. [18] conducted a probabilistic life cycle cost analysis for a Ground Source Heat Pump (GSHP) based on Monte Carlo method. They found that, from a life cycle perspective, the GSHP option was more favorable than the conventional system. Hang et al. [19] evaluated the solar water heating systems for typical US residential buildings from the energy consumption, economic, and environmental points of view. They considered flat-plate and evacuated-tube solar collectors. Their results showed that the flatplate solar water heating systems, using a natural gas auxiliary heating, had the best performance. Kegel et al. [20] conducted a life cycle cost analysis for several combinations of heat pumps with renewable sources under Canadian climatic conditions. Through optimization, and for a 20-year life cycle analysis, they found that a standard air source heat pump system was the most economical option for an energyefficient house. However, to our knowledge, no previous investigation has proposed or assessed ATES from the economic and environmental points of view. Therefore, the sub-objectives of this research paper are multi-fold and include:

- Designing a suitable confined aquifer to meet the cooling and heating energy needs of a residential building complex located in Tehran, Iran;

- Providing a comprehensive numerical model of the aquifer thermal energy storage and thermodynamic evaluation;

- Considering three different operational alternatives in combination with ATES;

- Noting economic and environmental considerations of the different operational alternatives;

- Using LCC method for economic considerations.

\section{Heating and cooling energy needs of the residential building complex}

A residential complex, consisting of 10 four-story buildings, located in Pounak region of Tehran was considered. Each floor consisted of 4 small apartments. The total floor area of the residential complex was $12800 \mathrm{~m}^{2}$. 
Hourly cooling and heating energy needs of the buildings were estimated using the software HAP 4.41 (Carrier) [6]. The building needed heating in 4 months of the year, beginning on November 21, and cooling in 4 months, beginning on May 21. The peak heating and cooling loads were estimated to be $0.504 \mathrm{MW}$ and $1.13 \mathrm{MW}$, respectively. The annual heating and cooling requirements of the complex were estimated to be 1.9 TJ and 8.7 TJ, respectively. Since the cooling requirement was much larger than that of the heating, we designed the ATES considering cooling requirement [6].

Presently, the heating and cooling needs of the buildings are met through gas-fired boilers, with supply and return hot water temperatures of 60 and $40^{\circ} \mathrm{C}$, respectively. Vapor-compression system, employing an environmentally safe refrigerant, is employed for cooling, with supply and return chilled water temperatures of 7 and $15^{\circ} \mathrm{C}$, respectively. Also, fan coils are employed in rooms for space heating and cooling.

\section{Utilizations of ATES for cooling and heating of the buildings}

We considered several alternatives to meet the heating and cooling energy requirements of the building complex. These alternatives were: direct cooling through ATES, coupling ATES with flat-plate solar collectors for heating, and finally coupling ATES with heat pump for both heating and cooling. These alternatives are briefly described below [6].

\subsection{Direct cooling through ATES}

In the ATES, water is withdrawn from the extraction well(s) in order to supply the thermal energy requirements of the building. In summer, cold water is withdrawn from the aquifer. It provides the cooling needs of the building by going through a heat exchanger. It is then injected back into aquifer through the injection well(s) and stored there for winter operation. In winter, water is withdrawn from the aquifer and it is cooled by going through a cooling tower and then injected back into the aquifer. Figure 1 shows the system operation in this alternative.
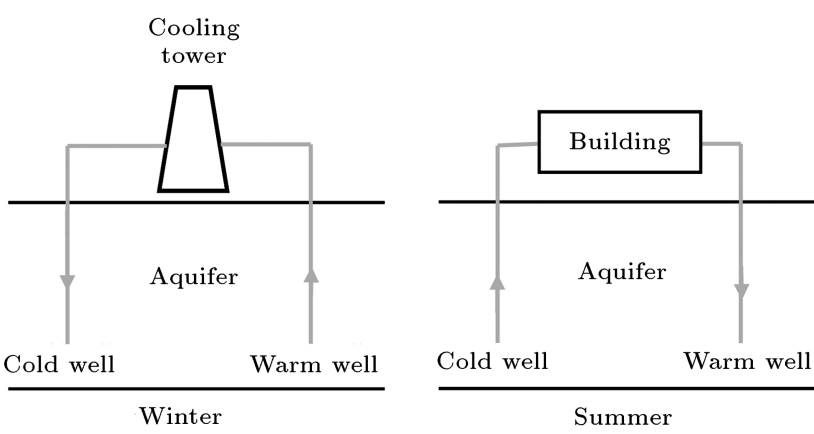

Figure 1. Direct Cooling through ATES.

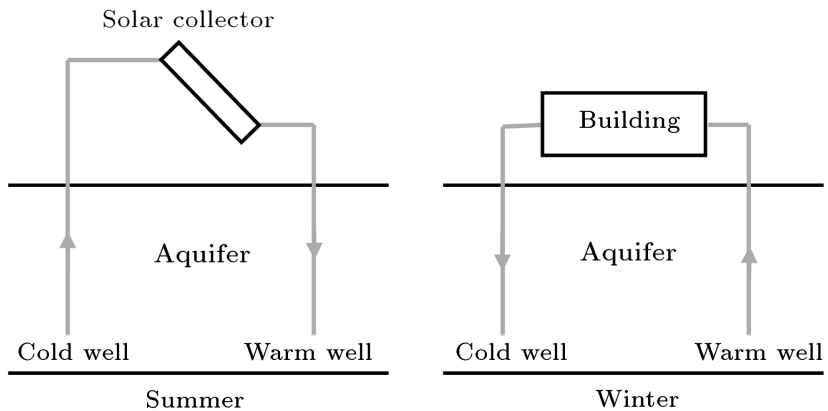

Figure 2. Heating by coupling of the ATES with flat-plate solar collectors.

\subsection{Coupling ATES with flat-plate solar collectors for heating}

Figure 2 shows an ATES, coupled with solar collectors. In this system, solar energy is utilized during the summer months to heat the water withdrawn from the aquifer. The heated water is then injected back into the aquifer. The stored warm water is withdrawn in winter to meet the heating needs of the building.

\subsection{Coupling of ATES with a heat pump for both cooling and heating}

Another alternative for ATES to meet the heating needs of buildings is its combination with a heat pump. Summer application of this alternative is same as the summer operation mode for the direct cooling alternative.

Warm water from aquifer acts as a lowtemperature heat source for the heat pump (see Figure 3 ). Since, in this study (for the building located in Tehran), the heating energy needs are much smaller than the cooling needs, only a portion of the withdrawn water is needed to pass through the heat pump to provide the low-temperature heat source for it. The other part of the withdrawn water passes through the cooling tower. These two parts of withdrawn water are combined and then injected back into the aquifer for summer cooling.

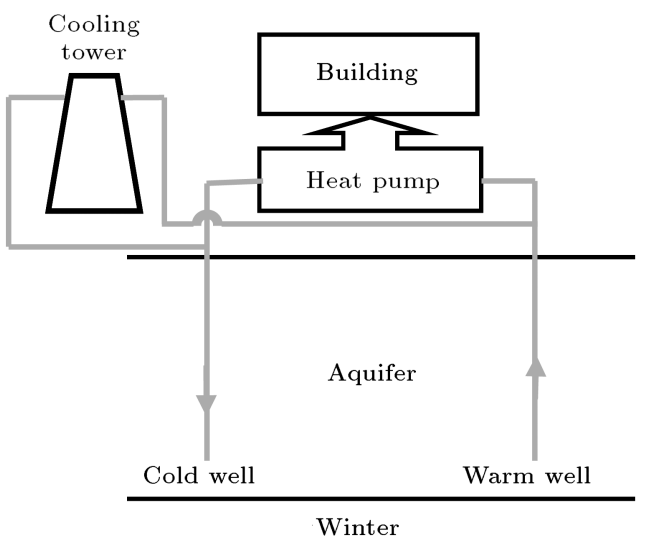

Figure 3. Combination of ATES with a heat pump for heating of the building (winter operation). 


\section{Modeling}

\subsection{Governing equations}

Thermo-hydraulic analysis of the aquifer performance requires calculation of the groundwater flow and the temperature distribution in the aquifer and its surrounding layers. In this section, theoretical principles of water flow and heat transfer phenomena for calculating the temperature distribution inside the aquifer are explained. The coupled groundwater and heat flow are governed by the partial differential equations describing the mass and energy balances in the aquifer.

The aquifer is a porous medium. The continuity equation in a porous medium may be expressed by the following equation [21]:

$$
\left[\frac{\partial(\rho \phi)}{\partial t}+\vec{\nabla} \cdot(\rho \vec{q})\right] d V=S_{f}
$$

where $S_{f}$ is related to source/sink term inside the porous medium and $\vec{q}$ is flow flux vector. It is obtained from the Darcy's equation:

$$
\vec{q}=-K \overrightarrow{\nabla h}
$$

which is the governing equation for the flow in a porous medium. In this equation, $K$ is the aquifer permeability.

The governing equation for heat transfer, including conduction and convection, is derived by applying the energy conservation principle in a porous medium [22]:

$$
\begin{aligned}
& p_{s} \frac{\partial T}{\partial t}=\nabla^{2}(\lambda T)-(\rho c)_{f} \vec{q} . \vec{\nabla} T+S_{H}, \\
& p_{s}=(\rho c)_{f} \phi+(\rho c)_{S}(1-\phi),
\end{aligned}
$$

where, $p_{s},(\rho c)_{f}$, and $(\rho c)_{s}$ are heat capacities per unit volume of aquifer, water, and the pebbles, respectively. Also, $T, q$, and $S_{H}$ are temperature, flow flux, and energy source/sink terms inside the aquifer, respectively, while $\lambda$ is a combined ratio that is a function of the thermal conductivity of water, pebbles, and aquifer porosity:

$$
\lambda=\phi k_{f}+(1-\phi) k_{s} .
$$

The main heat transfer phenomenon within the upper and lower surrounding layers of the aquifer is conduction. Therefore, we have:

$$
\frac{\partial T}{\partial t}=\alpha \nabla^{2} T
$$

\subsection{Numerical modeling}

In this research, the finite difference approach is employed for modeling of flow and temperature distri- bution in the confined aquifer under consideration, because of simple computational geometry and boundaries. Implementation and simulation in the finite difference method is simple. But, the quality of a finite difference approximation is often lower than that of the other corresponding approaches, such as finite element.

The computational domain is three-dimensional. Using finite difference approach is conventional in ATES flow and thermal modeling [21]. The flow and temperature equations are as follows:

$$
\begin{gathered}
\frac{\partial^{2} h}{\partial x^{2}}+\frac{\partial^{2} h}{\partial y^{2}}+\frac{\partial^{2} h}{\partial z^{2}}=-\frac{S_{f}(x, y, z)}{K \rho d V} \\
(\rho c)_{s} \frac{\partial T}{\partial t}=\lambda\left[\frac{\partial^{2} T}{\partial x^{2}}+\frac{\partial^{2} T}{\partial y^{2}}+\frac{\partial^{2} T}{\partial z^{2}}\right] \\
-(\rho c)_{f}\left[-K_{f}\left(\frac{\partial h}{\partial x} \vec{i}+\frac{\partial h}{\partial x} \vec{j}+\frac{\partial h}{\partial x} \vec{k}\right)\right] \\
\cdot\left(\frac{\partial T}{\partial x} \vec{i}+\frac{\partial T}{\partial x} \vec{j}+\frac{\partial T}{\partial x} \vec{k}\right)+S_{H} \\
\frac{\partial T}{\partial t}=\alpha\left[\frac{\partial^{2} T}{\partial x^{2}}+\frac{\partial^{2} T}{\partial y^{2}}+\frac{\partial^{2} T}{\partial z^{2}}\right]
\end{gathered}
$$

The first step in the finite difference method is discretization. The numerical solution of the above equations is performed by using fractional steps in three dimensions [23]. Initially, the equation is solved using Crank-Nicolson implicit method, and results of the solution in one direction (for example, $x$ direction) are used for solutions in other directions ( $y$ and $z$ directions). In any direction, the solution is performed by applying the Thomas's TDMA ${ }^{2}$ (Three Diagonal Matrix Algorithm) algorithm. Central difference scheme is used to discretize Eqs. (7), (8), and (9).

It should be noted that this method has secondorder truncation errors in each direction. The advantage of this procedure is its unconditional stability and higher rate of convergence, because of using the TDMA method [23].

\subsubsection{Meshing}

The computational domain was cubic and threedimensional. Since the boundary conditions in an aquifer are simple, using the uniform structured mesh is more applicable. Meshing was performed in such a way that injection/withdrawal wells were considered in all nodes of computational domain. Figure 4 shows the meshing arrangement.

For investigation of mesh size independency, so that a unique solution would be obtained, three series of mesh sizes were examined: $\Delta x=0.5 \mathrm{~m}, \Delta y=0.5 \mathrm{~m}$, $\Delta z=0.25 \mathrm{~m}$ with $\Delta t=0.5$ hours; $\Delta x=1 \mathrm{~m}$, 


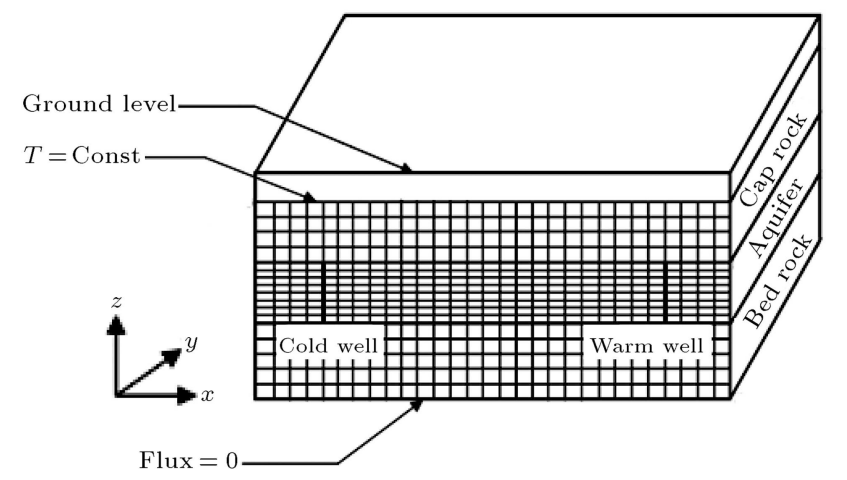

Figure 4. Three-dimensional computational domain.

$\Delta y=1 \mathrm{~m}, \Delta z=0.5 \mathrm{~m}$ with $\Delta t=1$ hours; and $\Delta x=5 \mathrm{~m}, \Delta y=5 \mathrm{~m}, \Delta z=2.5 \mathrm{~m}$ with $\Delta t=10$ hours. The parameter on which the error was estimated was recovery factor of the aquifer (see Section 4.2.3). The time of simulation was 2 years for all of them. We found out that the recovery factor differences between the first and the second series and between the second and the third series were 1 and 5 percent, respectively, since the stability condition was fulfilled. Therefore, the second series was selected as interval steps.

\subsubsection{Initial and boundary conditions}

The boundary condition at the upper layer of cap rock is constant temperature. It is assumed that in its depth, the temperature remains constant throughout the year and it is approximately equal to the yearly average of the ambient air temperature of the location (Tehran). At the lower layer of the bed rock, the boundary condition is thermally insulated. The sides are also assumed to be thermally isolated. The initial temperature in the model domain linearly increases from the top to the bottom to express the thermal equilibrium state prior to thermal injection.

According to the condition, a value is considered for flow rates of the injection/withdrawal wells. This value is considered as the source term in Eq. (1). By considering groundwater velocity, a pressure gradient is added in the direction of $x$ that is obtained from the Darcy equation. The initial head in the model domain is equal to the model elevation. Boundary condition on the lateral and the upper and lower sides is no flow.

\subsubsection{Energy recovery factor in the aquifer}

After determining the temperature field within the aquifer at different time steps, the amount of recovered energy from the aquifer is determined. The most important factor of ATES numerical modeling is the energy recovery factor. It indicates the amount of energy which can be recovered from the stored energy in the aquifer. Thermal energy recovery factor of an aquifer, $\eta_{A}$, is equal to the ratio of the extracted energy to the amount of injected energy, or:

$$
\eta_{A}=\frac{Q_{\text {withdraw }}}{Q_{\text {injection }}}
$$

\subsubsection{Coefficient of performance of the thermal energy storage system}

In air conditioning systems (heating or cooling), the coefficient of performance is defined as:

$$
\mathrm{COP}_{\text {system }}=\frac{Q_{\text {required }}}{W}
$$

where $Q_{\text {Required }}$ is the annual amount of energy requirement for cooling or heating of the building and $W$ is the total annual electrical energy consumed to run the circulation pumps, cooling tower fans, chillers, and heat pumps.

\section{Steps followed for the design of the ATES}

To determine the parameters of an ATES, the following data must be available:

\section{- Energy storage capacity;}

- The maximum injection/withdraw rate and the temperature difference.

In the aquifer thermal energy storage system considered in this study, first, the amount of energy required for cooling or heating of the building complex is estimated. The aquifer parameters, such as thickness, porosity, and permeability, are generally obtained from the hydrological data available at the site. In general, the aquifer parameters vary in the domain. To simplify the investigation, constant values are assumed in this study [6]. Table 1 shows the aquifer properties employed in the analysis.

After determining the aquifer characteristics and the heating/cooling requirements of the building, the storage system can be designed as follows [24]:

1. Determine the specific heat capacity $\left(p_{s}\right)$;

Table 1. Thermo-physical properties of the aquifer.

\begin{tabular}{ll}
\hline \multicolumn{1}{c}{ Property } & \multicolumn{1}{c}{ Value } \\
\hline Aquifer permeability & $0.0017 \mathrm{~m} / \mathrm{s}$ \\
Porosity & 0.3 \\
Density of water & $1000 \mathrm{~kg} / \mathrm{m}^{\mathbf{3}}$ \\
Density of pebbles & $1800 \mathrm{~kg} / \mathrm{m}^{\mathbf{3}}$ \\
Specific heat of water & $4200 \mathrm{~J} / \mathrm{kg} \mathrm{K}$ \\
Specific heat of pebbles & $1292 \mathrm{~J} / \mathrm{kg} \mathrm{K}$ \\
Thermal conductivity of water & $0.63 \mathrm{~W} / \mathrm{m} \mathrm{K}$ \\
Thermal conductivity of pebbles & $1.3 \mathrm{~W} / \mathrm{m} \mathrm{K}$ \\
\hline
\end{tabular}


2. Determine the recovery factor of the aquifer, $\eta_{A}$. The recovery factor is calculated via numerical simulations. The aquifer dimensions and properties are supplied as inputs. First, an approximate value for the recovery factor of the aquifer is assumed. Then, at the end of the simulation procedure and after determining distance of the wells, the value of the recovery factor is calculated;

3. The required storage volume is calculated from the following equation:

$$
V_{\text {storage }}=\frac{E_{\text {required }}}{p_{S} \Delta T \eta_{A}}
$$

By dividing the storage volume to the injection/withdraw period, the amount of injection/ withdrawal flow rate is obtained;

4. The horizontal area of the aquifer with the depth of $b$ is determined from:

$$
A=\frac{V_{\text {storage }}}{b} \text {. }
$$

5. The distance between the wells is obtained from the following relation [24]:

$$
R=\sqrt{A / 1.05} .
$$

6. With the known distance between wells and the injection/withdraw flow rate, the recovery factor of the aquifer is determined through the developed simulation code;

7. Steps 3 to 6 are repeated until the difference between the assumed and estimated values of the recovery factor of the aquifer is less than a certain amount.

\section{Economic model}

Economic investigation of energy systems can be conducted in two ways. One is the financial assessment that is used by buyers and only takes account of the capital and operational costs versus gained energy. Another method that has been used by governments and decision makers is called the economic assessment. In this method, all economic factors such as costs, taxes, and subsidies are generally considered. In the economic assessment, the following methods and factors are considered:

1. Life Cycle Cost (LCC) is the sum of all costs during application of the system based on the prices of the day;

2. Payback Period (PP) is the time required to recover all spent costs via incoming or saving money.

Economic evaluation based on the life cycle cost analysis is a perfect method for studying of commercial purposes.

\subsection{The actual value of costs}

In this method, not only the capital costs, but also the costs imposed during system operation are considered. The study period should be equal to the maximum lifetime of the elements of the considered system. After considering the capital investment and the operating and maintenance costs, it can be easy to detect the cheaper system by comparison. For a meaningful comparison, expenditures and revenues or costs and benefits should be expressed in the day worth of equivalent present value $(P W)$ in the future. For this purpose, the discount or interest rate is used as follows:

$$
P W=\operatorname{Pr} \times F W,
$$

where:

$$
\operatorname{Pr}=\frac{1}{(1+d)^{n}}
$$

where $P W, P r, d$, and $n$ are present worth, present worth factor, discount rate, and lifetime of the system, respectively. $F W$ is the future worth of revenues or incomings. The annual interest or discount rate $(d)$ is the depreciation percent of the invested capital in one year.

The economic calculation of the present values of the life cycle cost of expenditures or incoming includes two parts:

1. Single payment: The present worth of costs that are paid once in lifetime of the system (purchase, piping, and installation costs). The present value of a single payment can be obtained by replacing $F W$ in Eq. (15):

$$
P W=\operatorname{Pr} \times C r .
$$

$\mathrm{Cr}$ and $\mathrm{Pr}$ are the single payment cost and present worth factor, respectively. In this study, the piping and installation cost is assumed to be $5 \%$ of the total purchase cost;

2. Annual payment: The present worth of the expenditures that will be annually paid during lifetime of the system (operational and maintenance costs) and obtained as follows:

$$
\begin{aligned}
P W= & C a+C a\left(\frac{1}{1+d}\right)+C a\left(\frac{1}{1+d}\right)^{2}+\cdots \\
& +C a\left(\frac{1}{1+d}\right)^{n-1}
\end{aligned}
$$

By allocation of $x=\frac{1}{1+d}, \mathrm{Eq} \cdot$ (18) can be rewritten as:

$$
\sum_{i=0}^{\infty} x^{i}=1+x+x^{2}+\cdots=\frac{1}{1-x},
$$




$$
\begin{aligned}
P a & =1+x+x^{2}+\cdots+x^{n}=\frac{1}{1-x}-\sum_{i=n}^{\infty} x^{i} \\
& =\frac{1}{1-x}-x^{n} \sum_{i=0}^{\infty} x^{i}=\frac{1-x^{n}}{1-x} .
\end{aligned}
$$

Eq. (18) can be briefly rewritten as follows:

$$
P W=P a \times C a,
$$

where:

$$
P a=\frac{(1+d)^{n}-1}{d(1+d)^{n-1}} .
$$

$C a$ and $P a$ are the annual cost and the cumulative present worth factor, respectively. When the discount rate is smaller, the present worth factor is larger and by reduction of the discount rate, the costs that should be paid in the future gain higher actual worth [25]. The maintenance cost is usually considered as a portion of the purchase cost. In this study, this cost is assumed to be $2 \%$ of the capital investment at the first operational year.

\subsection{Life Cycle Cost (LCC)}

By using the present worth factor of $\mathrm{Pr}$ and $\mathrm{Pa}$ for all types of costs, the present worth can be calculated. The summation of all of the present worth is equal to the total cost that will be paid during lifetime of the system and is called LCC:

$$
\mathrm{LCC}=\sum_{i} P W_{i} .
$$

By having and comparing the LCCs of different systems, the suitable system can be selected economically [25].

\subsection{Annualized Life Cycle Cost (ALCC)}

This quantity is obtained by dividing LCC to the cumulative present worth factor and its unit is the currency per year:

$$
\mathrm{ALCC}=\frac{\mathrm{LCC}}{P a} .
$$

\subsection{Payback period}

This study is a comparative study; thus, the payback period is important in it. First, the energy production cost is calculated for the basic case based on the LCC method. This cost is our criterion for comparison. For determination of payback period, the expenditures for energy production in different systems and alternatives should be compared with each other. The relations for calculation of payback period are as follows:

$$
P W_{c}=P W_{b},
$$

$P W_{c}$ is the present worth of the total cost (single and annual costs) and $P W_{b}$ is the present worth of the incomings (cost of energy production in basic case). Then, we have:

$$
\mathrm{LCC}=E \times P \times\left[\frac{(1+d)^{n}-1}{d(1+d)^{n-1}}\right],
$$

where $n, d, E$, and $P$ are payback period, discount rate, annual energy production (energy requirement), and cost of energy production unit (basic case), respectively.

\section{Discussion of the results}

\subsection{Numerical model verification}

The important parameter in ATES system that has a key role on the performance of the system is the withdrawal temperature. A verification was performed by using the FLUENT software and simulation of computational domain. The computational domain is shown in Figure 5. In this meshing, an unstructured 3D mesh of 259346 cells was built. The chosen element was Tet/Hybrid and its type was TGrid. For validation of the cold and warm wells, temperatures were compared with the ones which had been obtained via the developed code (Table 2) during two years. The results show a good agreement between the developed code and the ones that were obtained using FLUENT.

\subsection{Design of the ATES system for cooling and heating of the building}

The input parameters are listed in Table 3. Design simulation is carried out as explained in Section 5. The results of the design simulation are listed in Table 4.

For cooling and heating of the building complex, we have coupled the ATES system with a heat pump. Since the annual cooling needs in TJ/year are much higher than the annual heating needs, we base our design on the annual cooling requirements. For this reason, when solar collectors are coupled with ATES for thermal energy storage for heating of the building complex, a much smaller aquifer would be needed.

The estimated pressure losses in the system are listed in Table 5 . These values were determined

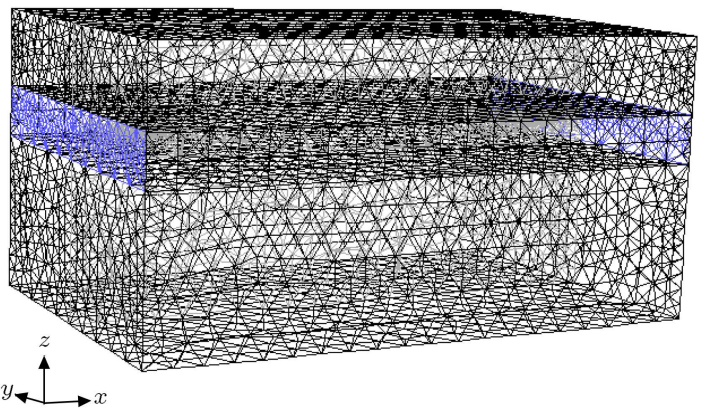

Figure 5. Model mesh in FLUENT. 
Table 2. Model verification with results of FLUENT simulation.

\begin{tabular}{cccccccc}
\hline \multirow{2}{*}{ (day) } & \multicolumn{2}{c}{ Warm well temperature } & & \multicolumn{3}{c}{ Cold well temperature } \\
\cline { 2 - 3 } \cline { 7 - 8 } & $\begin{array}{c}\boldsymbol{T}_{\text {FLUEN }} \\
\left({ }^{\circ} \mathbf{C}\right)\end{array}$ & $\begin{array}{c}\boldsymbol{T}_{\text {Code }} \\
\left({ }^{\circ} \mathbf{C}\right)\end{array}$ & $\begin{array}{c}\text { Error } \\
(\boldsymbol{\%})\end{array}$ & & $\begin{array}{c}\boldsymbol{T}_{\text {FLUENT }} \\
\left({ }^{\circ} \mathbf{C}\right)\end{array}$ & $\begin{array}{c}\boldsymbol{T}_{\text {Code }} \\
\left({ }^{\circ} \mathbf{C}\right)\end{array}$ & $\begin{array}{c}\text { Error } \\
(\boldsymbol{\%})\end{array}$ \\
\hline 90 & 12 & 12 & 0 & & 3 & 3 & 0 \\
180 & 12 & 12 & 0 & & 3 & 3.13 & 4.15 \\
270 & 14 & 14 & 0 & & 8.64 & 8.94 & 3.35 \\
360 & 13.31 & 13.86 & 3.96 & & 10.2 & 10.66 & 4.31 \\
450 & 12.35 & 12.8 & 3.51 & & 3 & 3 & 0 \\
540 & 11.89 & 12.34 & 3.64 & & 3.48 & 3.58 & 2.79 \\
630 & 14 & 14 & 0 & & 8.59 & 8.82 & 2.6 \\
720 & 14 & 13.86 & 1.01 & & 10.34 & 10.53 & 1.8 \\
\hline
\end{tabular}

Table 3. Input information for the design of the ATES system.

\begin{tabular}{lcc}
\hline \multicolumn{1}{c}{ Quantity } & $\begin{array}{c}\text { Cooling and a heat } \\
\text { pump coupled with } \\
\text { ATES for heating }\end{array}$ & $\begin{array}{c}\text { Flat-plate solar } \\
\text { collectors coupled with } \\
\text { ATES for heating }\end{array}$ \\
\hline Injection temperature in winter $\left({ }^{\circ} \mathrm{C}\right)$ & 3 & 43 \\
Injection temperature in summer $\left({ }^{\circ} \mathrm{C}\right)$ & 14 & 65 \\
Initial recovery factor of the aquifer $(\%)$ & 70 & 70 \\
Aquifer height $(\mathrm{m})$ & 16 & 16 \\
Cap rock height $(\mathrm{m})$ & 25 & 25 \\
Bed rock height $(\mathrm{m})$ & 50 & 50 \\
Groundwater velocity $(\mathrm{m} /$ year $)$ & 5 & 5 \\
Groundwater temperature $\left({ }^{\circ} \mathrm{C}\right)$ & 12 & 12 \\
Aquifer initial temperature $\left({ }^{\circ} \mathrm{C}\right)$ & 12 & 18 \\
The temperature of upper surface of & 18 & \\
the cap rock layer $\left({ }^{\circ} \mathrm{C}\right)$ & & 1.9 (heating requirements) \\
The energy that should be stored $(\mathrm{TJ} / \mathrm{y})$ & 8.7 (cooling requirements)
\end{tabular}

Table 4. Results of the different operational alternative designing.

\begin{tabular}{lcc}
\hline \multicolumn{1}{c}{ Quantity } & $\begin{array}{c}\text { Cooling and a heat } \\
\text { pump coupled with } \\
\text { ATES for heating }\end{array}$ & $\begin{array}{c}\text { Flat-plate solar } \\
\text { collectors coupled with } \\
\text { ATES for heating }\end{array}$ \\
\hline The recovery factor of the aquifer $(\%)$ & 73 & 63 \\
Aquifer length $(\mathrm{m})$ & 182 & 80 \\
Aquifer width $(\mathrm{m})$ & 116 & 32 \\
Injection/withdraw rate L/s & 32.5 & 7.5 \\
Aquifer volume $\left(\mathrm{m}^{3}\right)$ & 337080 & 35387 \\
The area of the horizontal surface of & 21067 & 2527 \\
the aquifer $\left(\mathrm{m}^{3}\right)$ & 142 & 50 \\
Distance of the wells $(\mathrm{m})$ & $x=20 \mathrm{~m}$ & $x=15 \mathrm{~m}$ \\
Coordination of cold well in horizontal & $y=58 \mathrm{~m}$ & $y=16 \mathrm{~m}$ \\
surface of the aquifer & $x=162 \mathrm{~m}$ & $x=65 \mathrm{~m}$ \\
Coordination of warm well in horizontal & $y=58 \mathrm{~m}$ & $y=16 \mathrm{~m}$ \\
surface of the aquifer & &
\end{tabular}


Table 5. Pressure losses for different sections of the ATES system.

\begin{tabular}{lccc}
\hline \multicolumn{1}{c}{ Unit } & $\begin{array}{c}\text { Direct } \\
\text { cooling }\end{array}$ & $\begin{array}{c}\text { ATES coupled } \\
\text { with heat } \\
\text { pump }\end{array}$ & $\begin{array}{c}\text { ATES coupled } \\
\text { with solar } \\
\text { collectors }\end{array}$ \\
\hline$\Delta P_{\text {friction loss }}(\mathrm{m})$ & 51.12 & 51.12 & 26.68 \\
$\Delta P_{\text {depth }}(\mathrm{m})$ & 45 & 45 & 40 \\
$\Delta P_{\text {well pairs }}(\mathrm{m})$ & 1.19 & 1.19 & 0.1 \\
$\Delta P_{\text {fitting }}(\mathrm{m})$ & 5 & 5 & 0.5 \\
$\Delta P_{\text {heat exchanger }}(\mathrm{m})$ & 2.25 & 2.25 & 1.2 \\
$\Delta P_{\text {heat pump }}(\mathrm{m})$ & - & 1.5 & - \\
$\Delta P_{\text {cooling towers }}(\mathrm{m})$ & 16 & 16 & - \\
$\Delta P_{\text {solar collectors }}(\mathrm{m})$ & - & - & 78.48 \\
$\Delta P_{\text {total }}(\mathrm{m})$ & 120.56 & 122.06 & \\
\hline
\end{tabular}

supposing $250 \mathrm{~m}$ of straight pipes, 10 elbows, a pipe diameter of $10 \mathrm{~cm}$ for the alternatives of direct cooling and the coupled ATES with heat pump and $5 \mathrm{~cm}$ of pipe for the coupled ATES with solar collectors, $2.5 \mathrm{~cm}$ of diameter for tube in the shell and tube heat exchanger with $5 \mathrm{~m}$ of length, and finally $45 \mathrm{~m}$ of depth for the wells. The head needed for the cooling tower pumps, and the pressure losses through the heat pump and the solar collectors were obtained from the manufacturers' catalogues [26-28]. The pressure losses due to friction were calculated from the Moody's diagram by considering the Reynolds number and roughness of the pipe that was supposed to be commercial steel.

\subsection{Economical assessment}

Table 6 shows the specifications and costs of the equipment that have been used in different alternatives and in the basic case [26-32]. For economic analysis and comparison of energy systems, the annualized capital cost, fuel cost, and maintenance cost should be calculated. The discount rate and lifetime of all of the systems have assumed to be $20 \%$ and 20 years, respectively. The electricity and natural prices are local prices in Iran that are considered to be $0.032 \$ / \mathrm{kWh}$ and $0.04 \$ / \mathrm{m}^{3}$, respectively.

The electricity and natural gas consumption in each of the abovementioned alternatives are obtained by using Ret Screen software. These values are obtained by this assumption such that all of these alternatives can satisfy heating and cooling requirements. In Figure 6, the electricity and natural gas consumption of the different alternatives and basic case are compared. In the alternatives of coupled ATES with heat pump and coupled ATES with solar collector, natural gas is not consumed and the heating of the building is satisfied through a new system. In the basic case and the alternative of direct cooling, the heating requirement is supplied via gas fired boiler and, therefore, these systems have the same natural gas consumption. The highest electricity consumption

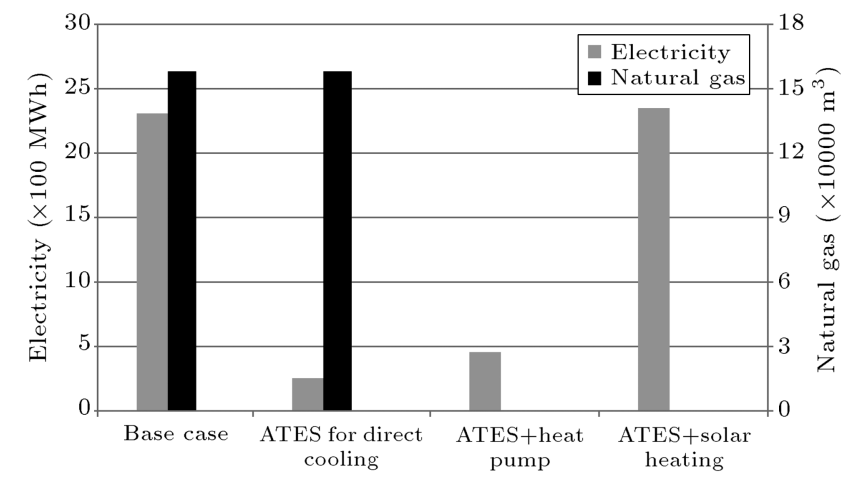

Figure 6. Comparison of energy consumption of different alternatives.

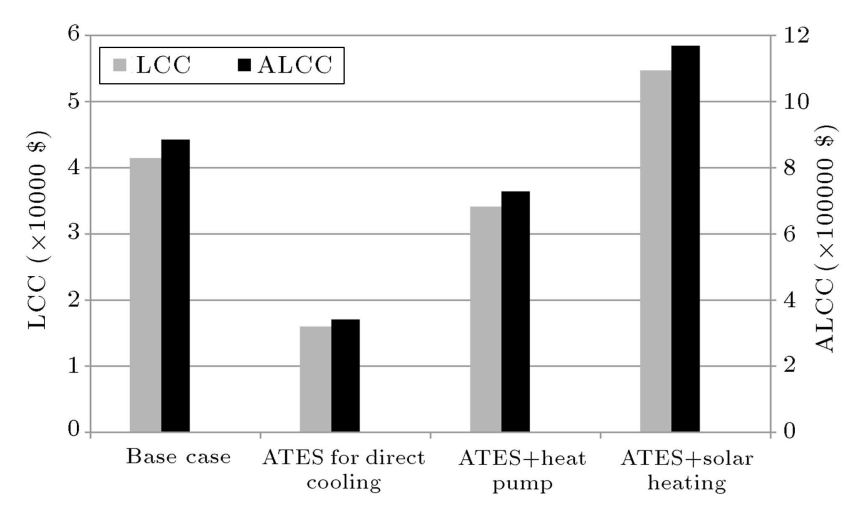

Figure 7. Comparison of LCCs and ALCCs of different alternatives.

is of compression chiller and, then, the consumption of the basic case and coupled ATES with solar collector is higher than that of other systems. In the direct cooling alternative, electricity consumption is less than other alternatives; this is also the case for the pump consumption.

In Figure 7, the values of LCC and ALCC are provided for different alternatives. The highest values are of the coupled ATES with solar collectors and the basic case, respectively. As seen in Table 6, the highest capital investment is of compression chiller that is used 
Table 6. Specifications of the equipment for different alternatives.

\begin{tabular}{|c|c|c|c|c|}
\hline Equipment & Specifications & Number & Manufacturer & Cost $(\$)$ \\
\hline \multicolumn{5}{|c|}{ Basic case } \\
\hline \multicolumn{5}{|l|}{ Cooling } \\
\hline Compression chiller & $\begin{array}{l}\text { Capacity: } 160 \mathrm{TR} \\
\text { Type: Screw }\end{array}$ & 2 & Sarma Afarin-Iran [29] & 228000 \\
\hline \multicolumn{5}{|l|}{ Heating } \\
\hline Boiler & $\begin{array}{l}\text { Capacity: } 600 \mathrm{~kW} \\
\text { Type: Water tube }\end{array}$ & 1 & Tahvieh Damavand-Iran [30] & 12000 \\
\hline \multicolumn{5}{|c|}{ ATES for direct cooling } \\
\hline \multicolumn{5}{|l|}{ Cooling } \\
\hline Pump & $\begin{array}{l}\text { Head: } 120 \mathrm{~m} \\
\text { Flow: } 32.5 \mathrm{~L} / \mathrm{s} \\
\text { Power: } 36 \mathrm{~kW}\end{array}$ & 2 & Pumpiran-Iran [31] & 9200 \\
\hline Heat exchanger & $\begin{array}{l}\text { Type: shell \& tube } \\
\text { Heat rate: } 1000000 \mathrm{kcal} / \mathrm{hr} \\
\text { Flow: } 515 \mathrm{gpm}\end{array}$ & 1 & Tehran Mobaddel-Iran [32] & 29400 \\
\hline Cooling tower & Flow: $515 \mathrm{gpm}$ & 1 & Damatajhiz-Iran [27] & 3800 \\
\hline Pipe & Steel & $300 \mathrm{~m}$ & Iran & 2400 \\
\hline Wells drilling & - & $120 \mathrm{~m}$ & Iran & 4800 \\
\hline Feasibility study & - & - & Iran & 8000 \\
\hline Ground preparing & - & - & Iran & 4000 \\
\hline Hydrology tests & - & - & Iran & 4000 \\
\hline Justifications & - & - & Iran & 20000 \\
\hline \multicolumn{5}{|l|}{ Heating } \\
\hline Boiler & $\begin{array}{l}\text { Capacity: } 600 \mathrm{~kW} \\
\text { Type: water tube }\end{array}$ & 1 & Tahvieh Damavand-Iran [30] & 12000 \\
\hline \multicolumn{5}{|c|}{ Coupled ATES with heat pump } \\
\hline \multicolumn{5}{|l|}{ Cooling } \\
\hline Pump & $\begin{array}{l}\text { Head: } 120 \mathrm{~m} \\
\text { Flow: } 32.5 \mathrm{~L} / \mathrm{s} \\
\text { Power: } 36 \mathrm{~kW}\end{array}$ & 2 & Pumpiran-Iran [31] & 9200 \\
\hline Heat exchanger & $\begin{array}{l}\text { Type: shell \& tube } \\
\text { Heat rate: } 1000000 \mathrm{kcal} / \mathrm{hr} \\
\text { Flow: } 515 \mathrm{gpm}\end{array}$ & 1 & Tehran Mobaddel-Iran [30] & 29400 \\
\hline Cooling tower & Flow: 515 gpm & 1 & Damatajhiz-Iran [27] & 3060 \\
\hline Pipe & steel & $300 \mathrm{~m}$ & Iran & 2400 \\
\hline Wells drilling & - & $120 \mathrm{~m}$ & Iran & 4800 \\
\hline Feasibility study & - & - & Iran & 8000 \\
\hline Ground preparing & - & - & Iran & 4000 \\
\hline Hydrology tests & - & - & Iran & 4000 \\
\hline Justifications & - & 一 & Iran & 20000 \\
\hline \multicolumn{5}{|l|}{ Heating } \\
\hline Heat pump & $\begin{array}{l}\text { Capacity: } 600 \mathrm{~kW} \\
\text { Type: water to water }\end{array}$ & 30 & Miami Heat Pump-USA [28] & 128000 \\
\hline
\end{tabular}


Table 6. Specifications of the equipment for different alternatives (countinued).

\begin{tabular}{|c|c|c|c|c|}
\hline Equipment & Specifications & Number & Manufacturer & Cost $(\$)$ \\
\hline \multicolumn{5}{|c|}{ Coupled ATES with solar collector } \\
\hline Cooling & & & & \\
\hline Compression chiller & $\begin{array}{l}\text { Capacity: } 160 \text { TR } \\
\text { Type: Screw }\end{array}$ & 2 & Sarma Afarin-Iran [29] & 228000 \\
\hline \multicolumn{5}{|l|}{ Heating } \\
\hline Pump & $\begin{array}{l}\text { Head: } 75 \mathrm{~m} \\
\text { Flow: } 7.5 \mathrm{~L} / \mathrm{s} \\
\text { Power: } 13 \mathrm{~kW}\end{array}$ & 2 & Pumpiran-Iran [31] & 4000 \\
\hline Heat exchanger & $\begin{array}{l}\text { Type: shell \& tube } \\
\text { Heat rate: } 300000 \mathrm{kcal} / \mathrm{hr} \\
\text { Flow: } 100 \mathrm{gpm}\end{array}$ & 1 & Tehran Mobaddel-Iran [32] & 11400 \\
\hline Solar collector & Type: Glazed & 450 & Watt-Poland [26] & 40000 \\
\hline Pipe & Steel & $300 \mathrm{~m}$ & Iran & 1800 \\
\hline Wells drilling & - & $120 \mathrm{~m}$ & Iran & 4800 \\
\hline Feasibility study & - & - & Iran & 8000 \\
\hline Ground preparing & - & - & Iran & 4000 \\
\hline Hydrology tests & - & - & Iran & 4000 \\
\hline Justifications & - & - & Iran & 20000 \\
\hline
\end{tabular}

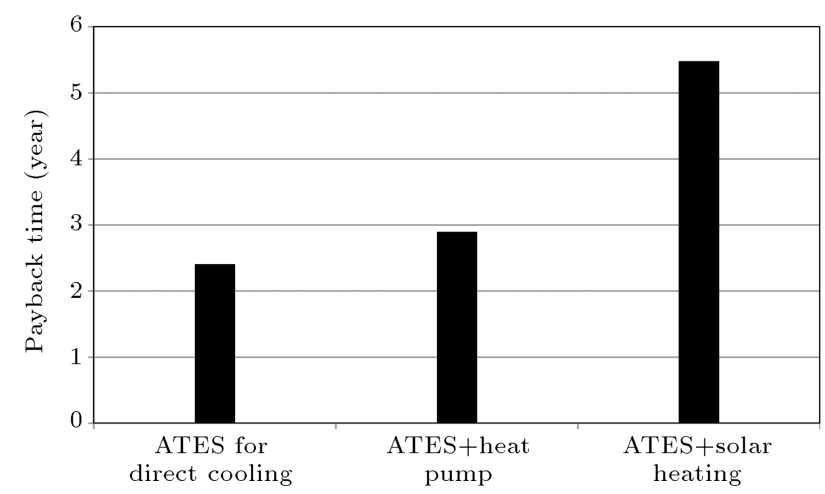

Figure 8. Payback time of different alternatives.

in these alternatives and has a greater portion in their LCC and ALCC. Moreover, the electricity consumption of these alternatives is too much that leads to high LCC and ALCC. The alternative of the direct cooling has the minimum LCC and ALCC because of its low capital investment.

Figure 8 shows the payback period of three investigated alternatives. Because of low capital investment and low operational cost of the alternative of the direct cooling, this alternative has the minimum payback period.

\subsection{Environmental assessment}

The main index of environmental sustainability of an energy system is the amount of $\mathrm{CO}_{2}$ emission. $\mathrm{CO}_{2}$ emission of different alternatives is shown in Figure 9.

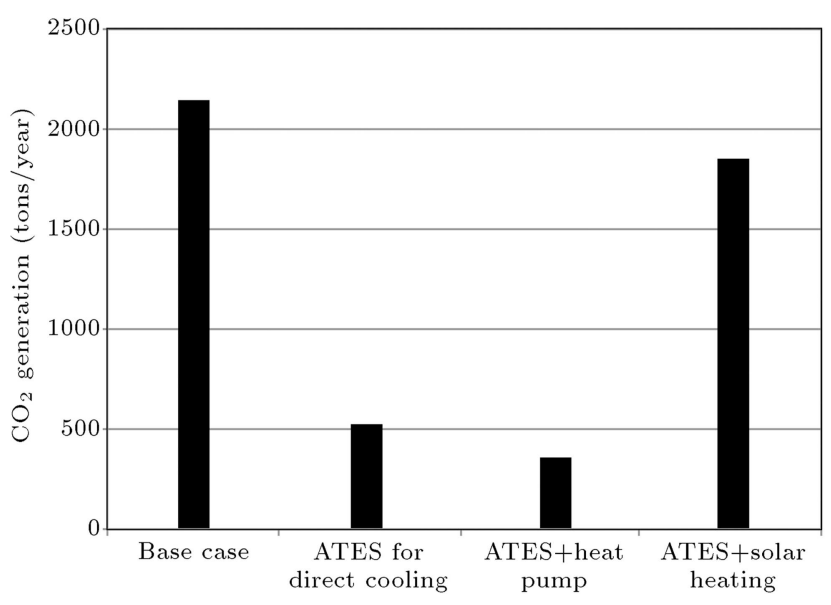

Figure 9. Comparison of $\mathrm{CO}_{2}$ emission of different alternatives.

The alternative of the coupled ATES with heat pump has low electricity consumption and zero natural gas consumption. Therefore, its $\mathrm{CO}_{2}$ emission is less than other alternatives. Also, the basic case has the maximum $\mathrm{CO}_{2}$ generation because of much electricity and natural gas consumption.

\section{Conclusion}

In this study, 3 different operational alternatives of ATES (using ATES for direct cooling, coupling of ATES with heat pump for both cooling and heating, 
and coupling of ATES with flat-plate solar collectors for heating) were economically and environmentally compared with each other and with the basic case. These systems were employed to store the thermal energy needs of a residential complex, located in Tehran, Iran. The objective was the storage of 8.7 TJ and 1.9 TJ of energy for summer cooling and winter heating, respectively. The LCC method and the Ret Screen version 4.0 software were used for economic and environmental assessment. The important concluding remarks of this research are the following:

- The highest fuel (electricity and natural gas) cost was for the basic case that was used as boiler and compression chiller for heating and cooling, respectively;

- The alternative of coupled ATES with solar collector and basic case had maximum and the alternative of ATES for cooling alone had minimum LCC;

- The payback periods of the alternatives of ATES for cooling alone, coupled ATES with heat pump for cooling and heating, and coupled ATES with flat-plate solar collectors were 2.41, 2.9, and 5.48, respectively;

- The alternative of coupled ATES with heat pump for heating and cooling had the minimum $\mathrm{CO}_{2}$ emission (359.32 tones/year).

\section{Nomenclature}

A Area, cross section $\left(\mathrm{m}^{2}\right)$

ALCC Annualized Life Cycle Cost (\$)

$b \quad$ Aquifer thickness $(\mathrm{m})$

c Specific heat $(\mathrm{J} / \mathrm{kgK})$

Ca Annual cost $(\$)$

$\mathrm{Cr} \quad$ Single payment cost $(\$)$

COP Coefficient Of Performance

d Discount rate (\%)

E Energy (J)

FW $\quad$ Future value $(\$)$

$g \quad$ Gravitational acceleration $\left(\mathrm{m} / \mathrm{s}^{2}\right)$

$h \quad$ Hydraulic head (m)

$K \quad$ Permeability $(\mathrm{m} / \mathrm{s})$

$k \quad$ Specific permeability $\left(\mathrm{m}^{2}\right)$

$L \quad$ Length $(\mathrm{m})$

LCC Life Cycle Cost $(\$)$

$n \quad$ Life time, payback (year)

$p \quad$ Specific heat capacity $\left(\mathrm{J} / \mathrm{m}^{3} \mathrm{~K}\right)$

$P \quad$ Price of energy production unit $(\$ / \mathrm{J})$

$\mathrm{Pa} \quad$ Cumulative present factor

$\begin{array}{ll}P r & \text { Present worth factor } \\ P W & \text { Present value }(\$) \\ q & \text { Specific velocity }(\mathrm{m} / \mathrm{s}) \\ Q & \text { Heat }(\mathrm{J}) \\ R & \text { Wells distance }(\mathrm{m}) \\ S & \text { Flow source term }(\mathrm{kg} / \mathrm{s}) \text { and heat } \\ & \text { source term }\left(\mathrm{J} / \mathrm{m}^{3} \mathrm{~K}\right) \\ t & \text { Time }(\mathrm{s}) \\ T & \text { Temperature }(\mathrm{K}) \\ V & \text { Volume }\left(\mathrm{m}^{3}\right) \\ \dot{V} & \text { Flow rate }\left(\mathrm{m}^{3} / \mathrm{s}\right)\end{array}$

Greek Symbols

$\begin{array}{ll}\alpha & \text { Diffusivity }\left(\mathrm{m}^{2} / \mathrm{s}\right) \\ \eta & \text { Efficiency } \\ \phi & \text { Porosity } \\ \lambda & \text { Aquifer thermal conductivity } \\ & (\mathrm{W} / \mathrm{m} / \mathrm{K}) \\ \rho & \text { Density }\left(\mathrm{kg} / \mathrm{m}^{3}\right)\end{array}$

\section{Subscripts}

$\begin{array}{ll}A & \text { Aquifer } \\ f & \text { Fluid } \\ g w & \text { Groundwater } \\ \text { imp } & \text { Imposed } \\ \text { injection } & \text { Injection } \\ O & \text { Overall } \\ \text { Rock } & \text { Rock or pebbles } \\ S & \text { Specific, solid } \\ V & \text { Void } \\ \text { water } & \text { Water } \\ \text { withdraw } & \text { Withdraw }\end{array}$

\section{References}

1. Dincer, I. "Renewable energy and sustainable development: a crucial review", Renewable and Sustainable Energy Reviews, 4, pp. 157-175 (2000).

2. Bakema, G., Snijders, A.L. and Nordell, B., Underground Thermal Energy Storage-State of the Art Report, Arnhem, Netherlands (1995).

3. Sanner, B., Karytsas, C., Menfrinos, D. and Rybach, L. "Current status of ground source heat pumps, and underground thermal energy storage, in Europe", Geothermics, 32, pp. 579-588 (2003).

4. Dincer, I. and Rosen, M.A., Thermal Energy Storage - Systems and Applications, Wiley Press, Chichester (2002). 
5. Kim, J., Lee, Y., Yoon, W.S., Jeon, J.S., Koo, M.H. and Keehm, Y. "Numerical modeling of aquifer thermal energy storage system", Energy, 35, pp. 49554965 (2010).

6. Ghaebi, H., Bahadori, M.N. and Saidi, M.H. "Performance analysis and parametric study of thermal energy storage in an aquifer coupled with a heat pump and solar collectors, for a residential complex in Tehran, Iran", Applied Thermal Engineering, 62, pp. 156-170 (2014).

7. Dickinson, J.S., Buik, N., Matthews, M.C. and Snijders, A. "Aquifer thermal energy: theoretical and operational analysis", Geotechnique, 59, pp. 249-260 (2009).

8. Novo, V.A., Bayon, R.J., Castro-Fresno, D. and Rodriguez-Hernandez, R. "Review of seasonal heat storage in large basins: water tanks and gravel water pits", Applied Energy, 87, pp. 390-397 (2010).

9. Preene, M. and Powrie, W. "Ground energy systems: delivering the potential", Energy, 84, pp. 77-84 (2009).

10. Sommer, W., Valstar, J., Leusbrock, I., Grotenhuis, T. and Rijnaarts, H. "Optimization and spatial pattern of large-scale aquifer thermal energy storage", Applied Energy, 137, pp. 322-337 (2015).

11. Jeon, J.S., Lee, S.R., Pasquinelli, L. and Fabricius, I.L. "Sensitivity analysis of recovery efficiency in hightemperature aquifer thermal energy storage with single well", Energy, 90, pp. 1349-1359 (2015).

12. Bloemendal, M., Olsthoorn, Th. and Boons, F. "How to achieve optimal and sustainable use of the subsurface for aquifer thermal energy storage", Energy Policy, 66, pp. 104-114 (2014).

13. Zeghicia, R.M., Essink, G.H.P.O., Hartogc, N. and Sommer, W. "Integrated assessment of variable density-viscosity groundwater flow for a high temperature mono-well aquifer thermal energy storage (HTATES) system in a geothermal reservoir", Geothermics, 55, pp. 58-68 (2015).

14. Sethia, V.P. and Sharma, S.K. "Greenhouse heating and cooling using aquifer water", Energy, 32, pp. 14141421 (2007).

15. Sethia, V.P. and Sharma, S.K. "Experimental and economic study of a greenhouse thermal control system using aquifer water", Energy Conversion and Management, 48, pp. 306-319 (2007).

16. Gaine, K. and Duffy, A. "A life cycle cost analysis of large-scale thermal energy storage technologies for buildings using combined heat and power", Zero Emission Buildings - Proceedings of Renewable Energy Conference, Trondheim, Norway (2010).

17. Vanhoudt, D., Desmedta, J., Van Baela, J., Robeynb, N. and Hoe, H. "An aquifer thermal storage system in a Belgian hospital: Long-term experimental evaluation of energy and cost savings", Energy and Buildings, 43, pp. 3657-3665 (2011).

18. Zhua, Y., Tao, Y. and Rayegan, R. "A comparison of deterministic and probabilistic life cycle cost analyses of ground source heat pump (GSHP) applications in hot and humid climate", Energy and Buildings, 55, pp. 312-321 (2012).

19. Hang, Y., Qu, M. and Zhao, F. "Economical- and environmental life cycle analysis of solar hot water systems in the United States", Energy and Buildings, 45, pp. 181-188 (2012).

20. Kegel, M., Sunye, R. and Tamasauskas, J. "Life cycle cost comparison and optimization of different heat pump systems in the Canadian climate", Proceedings of e-Sim: The Canadian Conference on Building Simulation, pp. 492-506 (2012).

21. Bear, J., Dynamics of Fluids in Porous Media, Elsevier, Dover Publication Inc., pp. 450-510 (1992).

22. Bejan, A., Convective Heat Transfer, McGraw Hill Press, New York (1997).

23. Hoffmann, K.A. and Chiang, S.T., Computational Fluid Dynamic, Publication of Engineering education System, USA (2000).

24. Schaetzle, W.J., Thermal Energy Storage in Aquifers, Design and Applications, Pergamon Press, New York (1980).

25. Pehnt, M. "Dynamic life cycle assessment (LCA) of renewable energy technologies", Renewable Energy, 31, pp. 55-71 (2005).

26. www.watt.pl/en (Accessed 30 March 2015).

27. www.damatazhiz.com (Accessed 30 March 2015).

28. www.heatpumpsuppliers.com (Accessed 30 March 2015).

29. www.ssi.co.ir (Accessed 30 March 2015).

30. www.damavandac.com (Accessed 30 March 2015).

31. www.pumpiran.com (Accessed 30 March 2015).

32. www.tehranmobaddel.com (Accessed 30 March 2015).

\section{Biographies}

Hadi Ghaebi is Assistant Professor in the Mechanical Engineering Faculty of Mohaghegh Ardabili University, Ardabil, Iran. He received his $\mathrm{PhD}$ degree from Sharif University of Technology, Tehran, Iran, in 2014. His research areas include thermal system design and optimization, renewable energy technologies, net zero energy buildings, and hydrogen and fuel cells.

Mehdi N. Bahadori received his $\mathrm{PhD}$ degree in Mechanical Engineering from the University of Illinois, 
USA, in 1964, and is currently Professor of Mechanical Engineering at Sharif University of Technology, Tehran, Iran. His research interests include natural cooling systems, solar energy utilization, environmentally compatible energy systems, development of indigenous technology, application of scientific-spiritual thinking to social problems, entropy and awareness, and engineering ethics and engineering of ethics.
Mohammad Hassan Saidi is Professor in the School of Mechanical Engineering at Sharif University of Technology, Tehran, Iran. His current research interests include MEMS, heat transfer enhancement in boiling and condensation, modeling of pulse tube refrigeration, vortex tube refrigerators, indoor air quality and clean room technology, energy efficiency in home appliances, and desiccant cooling systems. 